\title{
Impact of Mobile Ad Wearout on Consumer Irritation, Perceived Intrusiveness, Engagement, and Loyalty: A PLS-SEM Analysis
}

Ahmad A.M. Alwreikat, Cyprus International University, Nicosia, Cyprus

Husam Rjoub, Cyprus International University, Nicosia, Cyprus

\section{ABSTRACT}

Mobile and smart devices provide a platform for firms/brands to communicate directly with past, present, or potential consumers (via online pop-ups, sponsored ads, ads on social media messengers, timelines, walls, etc.). Existing research on human-mobile interaction and end-user mobile management only highlights the positive fronts of repetitive exposures to mobile ads, ignoring the negative. The present study examines the effects of mobile ad wearout on irritation, intrusiveness, engagement, and loyalty via social media outlets. Survey data were solicited from consumers in Jordan, and the partial least squares structural equation modeling (PLS-SEM) technique was applied. Results show that mobile ad wearout is a strong determinant for increased consumer irritation and perceived intrusiveness. Intrusiveness resulted in lower levels of consumer engagement and higher levels of consumer loyalty. Irritation resulted in lower levels of consumer engagement; no changes were observed in consumer loyalty. This study shows managers how mobile ad wearout causes irritation and intrusiveness, which diminishes consumer engagement and 1oyalty. In essence, managers can gain insights on the positive and negative outcomes of mobile ad wearout. Implications for theory and practice are discussed.

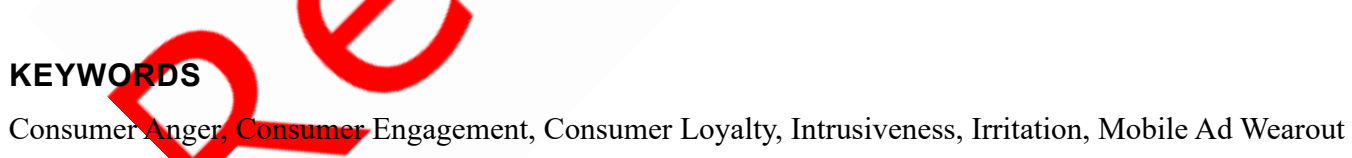

\section{INTRODUCTION}

Mobile and smart devices are changing the way customers and businesses interact with each other, such as through personalized experiences and advertisements (Arya, Bhadoria, \& Chaudhari, 2018; Bhadoria, Chaudhari, Tomar, \& Singh, 2017). eMarketer (2015) showed that about $88 \%$ of U.S. firms are using at least one social networking site (Twitter, Facebook, Instagram, Pinterest, Snapchat, etc.) for marketing purposes. Internetworldstats (2020) reported that this trend is expected to spread to other countries with a high literacy and Internet-penetration rate, such as Jordan (85.3\%). According to a Statista (2019) report, there has been a dramatic increase in the number of social media users,

\section{DOI: 10.4018/JOEUC.20210501.oa5}

This article, published as an Open Access article on April 2, 2021 in the gold Open Access journal, Journal of Organizational and End User Computing (converted to gold Open Access January 1, 2021), is distributed under the terms of the Creative Commons Attribution License (http://creativecommons.org/licenses/by/4.0/) which permits unrestricted use, distribution, and production in any medium, provided the author of the original work and original publication source are properly credited. 
from 0.97 billion in 2010 to 2.82 billion in 2019, worldwide. Facets of mobile technology that have been discussed and debated in the literature include ubiquity, deep learning, privacy issues, and personalized advertisements (Gupta, Agrawal, \& Yamaguchi, 2019; Gupta, Yamaguchi, \& Agrawal, 2018; Jararweh et al., 2017). Personalized marketing and advertisements via mobile and social media outlets are expected to grow (Tucker, 2014).

Research showed that marketers and advertisers in the United States will spend around $\$ 43.9$ billion this year on mobile ads (Benes, 2019). Biometric computing and recognition have become prevalent in personalized marketing (Arya \& Bhadoria, 2019), which is why mobile devices are highly individualized and are important personal communication tools (Bacile, Ye, \& Swilley, 2014). Shawky (2019) argued that less accessible consumer segments can be reached through social media and mobile platforms ads. Existing literature showed that personalized mobile ads are antecedents of high brand loyalty, brand attachment, brand engagement, positive attitude, perceived quality, and intention to forward the ads (e.g., Di Gangi \& Wasko, 2016; Grewal et al., 2016; Shanahan, Tran, \& Taylor, 2019; Tucker, 2014; Walrave et al., 2019).

In this study, Mobile Ad Wearout represents excessive exposure to the same marketing and advertising campaigns. Mobile and pop-up ads do not only affect the human-mobile interaction experience, but also install negative feelings and, as such, are generally unwanted marketing and advertising channels. Past scholars focused mostly on the positive outcomes of mobile ads (Tucker, 2014; Walrave et al., 2019), which misled marketing managers to think that repetition and high exposure to personalized mobile ads is a way to attract and retain consumers. However, mobile ads can be disturbing due to the nature of their execution (e.g., too loud or too long) or placement (e.g., too many or too frequent), and their execution process may cause unfavorable spillover effects on marketing and advertising efforts (Brechman et al.,2016). Extant theoretical discussions illustrated that Mobile Ad Wearout can cause privacy concerns, for example, intrusiveness and irritation among consumers.

Consequently, the human-device interaction experience can be a barrier for engagement between scientific end-user developers (Segal, \& Morris, 2011) and can affect usage behavior among social media users (Amos, Zhang, \& Pentina, 2014, Di Gangi \& Wasko, 2016). In this study, the humandevice interaction experience is users' experiences with Mobile Ad Wearout. Surprisingly, studies that investigated Ad Wearout were mostly in an offline context and in Western nations (Naik et al., 1998; Pechmann \& Stewart, 1990; Reggy, 1999; Royo-Vela \& Meyer, 2016). To the best of the author(s) knowledge, there are no studies on Mobile Ad Wearout in the Arabian context. The aim of this paper is to examine the impact of Mobile Ad Wearout on perceived consumer intrusiveness and irritation, and the impact of perceived consumer intrusiveness and irritation on consumer loyalty and engagement. A partial teast squares structural equation modeling (PLS-SEM) technique is deployed to examine these relationships. The PLS-SEM technique showcases the variance explained in the outcome variable by the predictor variable (Hair et al., 2017), and its "causal-predictive" power ensures a balance between theoretical construct explanation, causes, and prediction (Abubakar, \& Al-zyoud, 2020; Shmueli et al., 2019).

The remainder of this paper is organized as follows. In Section 2, we review the literature on the concepts under investigation and conclude with hypotheses development. In Section 3, we present the research instruments, data collection, and sampling approach. Section 4 presents the research data analyses techniques and results, and Section 5 presents a discussion of the findings, implications, research limitations, and future recommendations. Section 6 presents the concluding comments.

\section{THEORETICAL BACKGROUND AND HYPOTHESES}

Mobile Ad Wear-in is a process by which consumers become familiar with the marketing and ad messages. According to Chen, Yang, and Smith (2016), "initial exposures to new ads and marketing messages create a positive feeling by reducing perceived uncertainty and serve as a medium for 
learning about brand and/or brand awareness" (p. 336). Mobile Ad Wearout occurs when consumers are repeatedly exposed to the same ads and marketing message (Pechmann \& Stewart, 1990; Peggy, 1999). Offline Wearout has a negative effect on consumers' attitudes towards advertising and/or marketing messages of a brand or firm (Naik et al., 1998; Royo-Vela \& Meyer, 2016). Among other perceptions, perceived privacy invasion can change the effect of marketing campaigns from positive to negative attitudes toward the firm or brand (Tsai et al., 2011; Tucker, 2014) and can cause irritation towards the campaigner (Lin \& Chen, 2015).

Consumer irritation towards ads and marketing messages is defined as being more negative than dislike; it is "provoking, causing displeasure and momentary impatience" (Aaker \& Bruzzone 1985, p. 48). Ad content can cause irritation, such as from repetitive content, execution, or placement, as with annoying pop-ups at private times or while chatting (Brechman et al. 2016; Duncan \& Nelson, 1985; Royo-Vela \& Meyer, 2016). Perceived consumer intrusiveness is the degree to which advertisements in a media vehicle interrupt the flow and goals of the viewer or consumer (Ha, 1996). Intrusiveness as a psychological consequence occurs when consumers' cognitive processes are interrupted, such as blocking or interrupting access to content. Intrusiveness and irritation are viewed as a major cause of annoyance and ad avoidance (Tsai et al., 2011; Tucker, 2014). On the other hand, brands and firms are interested in pursuing consumer loyalty and engagement because of theirlinks to secure profitability and long-term sustainability (Shankar \& Jebarajakirthy, 2019

Repetition allows consumers to process and digest advertisement and marketing messages easily. According to Alwitt and Mitchell (1985), a high number of message repetitions increases the level of persuasion and enhances the tendency to recall an advertisement's message; however, over time, repetition may result in wearout because high exposure frequencies induce expressions of displeasure and annoyance (Cacioppo \& Petty, 1980; Rau et al., 2014). Rau,Zhou, Chen, and Lu (2014) added that repetition can arouse a feeling of tedium or psychologicalreactance that ultimately proves detrimental to persuasion. Incessant repetition affects consumers perceptions of the firm's effort and credibility (Kirmani, 1997). In the context of this research, Mobile Ad Wearout denotes the high frequency at which individuals are exposed to a mobile advertisement in a day.

In human-mobile interaction experiences, the effect of repetition in mobile advertisements and marketing is initially positive, because consumers develop positive attitudes as familiarity increases. However, when familiarity reaches its saturation level, additional exposures to the same messages may result in boredom and negative thoughts that outweigh positive ones. Wearout can reduce ad effectiveness and brand preference (Goldstein et al., 2014). Research showed that more ad repetition can hurt a brand, because consumers who encounter the same ads repeatedly can become weary and turned off (Kronrod, \& Huber, 2019). Schmidt and Eisend's (2015) meta-analysis showed that the effect of traditional advertising repetition on consumer attitude can be both positive outcomes (e.g., habituation, positive thoughts like loyalty and recommendations) and negative outcomes (e.g., anger, boredom, etc.). This has received additional support from past work (Brechman et al., 2016; Tsai et al., 2011; Tucker, 2014). These relationships have received little attention in the context of mobile ads. In particular, how firms conduct their marketing and advertising campaigns, causing Mobile Ad Wearout, leads to unwanted behavioral responses. Based on these arguments, the following hypotheses are proposed:

H1: Mobile Ad Wearout will influence irritation among consumers.

H2: Mobile Ad Wearout will influence perceived intrusiveness among consumers.

Consumer engagement is a mental state of being contained to, engrossed with, and devoting attention to a firm or brand (Triantafillidou \& Siomkos, 2018). According to Hollebeek et al. (2014), consumer engagement is a psychological state that "evolves through cognitive, affective and behavioral processes spanning from learning (gaining knowledge around brands), sharing (information and experiences), advocating (recommending brands), socializing (developing attitudes toward the 
community), and co-developing products" (p. 155). Consumer loyalty is the tendency of a buyer to patronize a brand, product, or firm revealed through behavioral and affective actions that can be quantified (i.e., increased commitment, continuance, and repurchase), as noted by Keiningham, Aksoy, and Williams (2009). In the context of mobile platforms, consumer loyalty reflects the tendency of users to regularly visit a brand's or firm's website and purchase and share positive, online word of mouth (WOM), as noted by Kaya et al. (2019).

Irritation evokes retaliatory behaviors toward the brand perceived to be responsible for the negative event and emotion. Negative emotions, such as irritation, anger, dislike, and discontent can predict consumer behavior (Romani et al., 2012; Sung \& Yih, 2019). Dickinger et al. (2004) advised marketers to consider the frequency of ad messages sent to consumers, and Royo-Vela and Luna (2012) argued that a high rate of ad messages can lead to negative attitudes towards the brand or firm. These attitudes and behaviors are likely to encourage negative consumer behaviors such as complaining, boycotting, spreading negative WOM information, persuading other customers frompurchasing the brand, and so forth (Abubakar et al., 2017; Antonetti, 2016; Riaz \& Khan, 2016; Romaniet al., 2012; Sung \& Yih, 2019). Mobile Ad Wearout resulted in lower click-through rates (the ratio of users who click on a specific link to the number of total users who view a page, email, or advertisement) among consumers (Försch \& de Haan, 2018). Based on the extant theoretical claims, this study theorizes that irritation may deteriorate the level of consumer engagement and loyalty.

H3: Consumer perceived irritation will influence consumerengagement H4: Consumer perceived irritation will influence consumer loyalty.

In a consumption context, intrusion evokes unwanted behaviors among consumers. From human-mobile device interaction perspective, end-user mobile management, privacy and security, and performance of apps are important in relation to Mobile Ad Wearout, and repetitive ads can raise privacy concerns or the perception of intrusiveness (Grewal et al., 2016). These feelings are likely to encourage negative reactions towards the advertising and/or marketing messages (Tsai et al., 2011; Tucker, 2014). Research has shown that the intrusiveness of ads and marketing messages acts as an antecedent of negative attitudes, such as a reduction in click-through rates, toward a firm or brand (Aguirre et al., 2015; Schmidt \& Eisend, 2015). As the level of perceived intrusiveness of ads and marketing messages increases, consumers are likely to ignore them and exhibit tedium reactions towards the firm or brand. Based on the extant theoretical claims, this study theorizes that perceived intrusiveness may deteriorate the level of consumer engagement and loyalty.

H5: Consumer perceived intrusiveness will influence consumer engagement.

H6: Consumer perceived intrusiveness will influence consumer loyalty.

\section{METHODS}

\section{Measures}

Mobile Ad Wearout was assessed with a three-item measure from Royo-Vela and Meyer (2016); the items were modified to fit the context and interest of the present research. Consumers were asked to rate the extent to which they agreed with statements such as "This brand repeatedly sends the same mobile ads through (e.g., Facebook, Instagram, Twitter etc.)."

Consumer Irritation was assessed with a two-item measure from Royo-Vela and Meyer (2016), which was adapted from Duncan and Nelson's (1985) studies. Consumers were asked to reflect upon the level of irritation caused by mobile ads, by responding to items such as "I consider mobile advertising messages as irritating." 
Perceived consumer intrusiveness was assessed with a two-item measure from Li, Edwards, and Lee (2002). Consumers were asked rate the extent to which they agreed with statements such as "I perceive mobile advertisements as intrusive."

Consumer engagement was assessed with an eight-item measure from Hollebeek et al. (2014). Consumers were asked rate the extent to which they agreed with statements such as "I spend a lot of time using this online brand community compared to others."

Consumer loyalty was assessed with a three-item measure from Keiningham et al. (2009), which was adapted from Noble, Griffith, and Adjei (2006) to reflect consumer loyalty by responding to items such as "As a customer, I am strongly loyal to this brand." All the measures were operationalized on a five-point response format ( $1=$ strongly disagree to $5=$ strongly agree). See Appendix for survey items.

\section{Sampling and Data Collection}

The original survey items were translated from English to Arabic and back-translated by linguistic professionals. A pilot study was conducted with 15 participants to ensure that participants had no difficulties understanding the questions, and some rephrasing and rewording were conducted to adhere to the target's cultural understandings. Jordan, officially the Hashemite Kingdom of Jordan, is an Arabian country with a population of approximately 10 million. According to the United Nations Educational, Scientific, and Cultural Organization (UNESCO), the literacy rate in the country is around 98.01\%. The context of this study suits the Jordanian population well, given the level of literacy, the number of mobile connections (8.23 million), the number of Internet users (6.78 million), and the number of social media users (5.70 million) as of 2020 (Datareportal, 2020). Participants were Jordanian consumers (the face-to-face survey was carried out in Amman, Jordan) recruited through a simple random sampling technique to acquire a representative sample and to increase the reliability of the research outcomes (Jahmani et al., 2018).

Participation was voluntary, and respondents were assured full confidentiality to reduce common method bias (Podsakoff et al., 2012). In order to ensure that the surveys were completed by the correct sources, we used the filter question. Can you think of any brand/company that REPEATEDLY sends you mobile ads via social media outlets (i.e., Facebook, Instagram, Twitter, LinkedIn, and others). Those who said "NO" were excluded from the study. Those who said "YES" were asked to name the brand/company and, in response to the ads messages they received, the respondents were asked to rate the study variables based on their perceptions and feelings. A total of 600 survey packets were printed, and 415 valid responses were retrieved, yielding a $69 \%$ response rate. Responses with missing values and incomplete information were eliminated; thus, 388 valid responses were used for analysis. Demographic variables considered in this study are gender, age, education, and frequency of checking mobile phones (times), including at work, walking, while using the toilet, and in-between sleep sessions. Results from a frequency analysis are illustrated in Table 1.

\section{ANALYSIS AND RESULTS}

\section{Analytical Framework}

Following Ringle, Wende, and Becker's (2015) recommendation, a partial least squares structural equation modeling (PLS-SEM) technique was applied to test the proposed hypotheses (SmartPLS 3 software). A previous version of PLS-SEM software was initially developed for prediction purposes. Hair, Hult, Ringle, and Sarstedt (2017) stated that the capability of the software has been extended to enable theory testing, which makes it suitable for exploratory, confirmatory, and predictive analyses (Henseler, Hubona, \& Ray, 2016). Table 2 presents the reliability and convergent validity of the measurement model. First, indicators with the standardized factor loadings above 0.50 were retained (see Figure 1, outer model) and were statistically significant above 1.960 (see Figure 2, outer model). Three indicators from the consumer engagement variable were eliminated due to low factor loading 
Table 1. Demographic breakdown

\begin{tabular}{|c|c|c|}
\hline Demographic Variables & Frequency & Percentage( $\%)$ \\
\hline \multicolumn{3}{|l|}{ Gender } \\
\hline Male & 267 & $68.8 \%$ \\
\hline Female & 121 & $31.2 \%$ \\
\hline Total & 388 & $100.0 \%$ \\
\hline \multicolumn{3}{|l|}{ Age } \\
\hline Under 20 & 93 & $24.0 \%$ \\
\hline $21-30$ & 263 & $67.8 \%$ \\
\hline $31-40$ & 4 & $1.0 \%$ \\
\hline $41-50$ & 18 & $4.6 \%$ \\
\hline Over 51 & 10 & $2.6 \%$ \\
\hline Total & 388 & $100.0 \%$ \\
\hline \multicolumn{3}{|l|}{ Level of education } \\
\hline High School & 0 & $0.0 \%$ \\
\hline Some College & 55 & $14.2 \%$ \\
\hline Bachelor's Degree & 134 & $34.5 \%$ \\
\hline Higher Degree & 199 & $51.3 \%$ \\
\hline Total & 388 & $100.0 \%$ \\
\hline \multicolumn{3}{|c|}{ Frequency of checking mobile phones (times) } \\
\hline $1-15$ times & 55 & $14.2 \%$ \\
\hline $16-30$ times & 267 & $68.8 \%$ \\
\hline More than 30 times & 66 & $17.0 \%$ \\
\hline Total & 388 & $100.0 \%$ \\
\hline
\end{tabular}

(refer to the Appendix for eliminated items). Table 2 ilhustrates that the Cronbach alpha ( $\alpha$ ), DijkstraHenseler's reliability (rho_A), and the composite reliability $(\mathrm{CR})$ of the variables under investigation have values above the threshold of 0.70 . These results collectively demonstrate adequate construct reliability and internal consistency.

Second, Table 2 illustrates that the variables under investigation have exhibited an average variance extracted (AVE) that is greater than the 0.50 threshold (Hair et al., 2017), suggesting the adequate convergent validity of each variable. The Fornell-Larcker matrix and heterotrait-monotrait ratio of correlations (HTMT index) were deployed to examine the divergent validity (the parameter showing that each variable explains more of the variance of its indicators than the indicators of the other constructs) of the variables under investigation. Table 3 illustrates that none of the inter-correlations were above the square root of each variable AVE (in bold-diagonal); this satisfies the criterion for divergent validity (Fornell \& Larcker, 1981; Yakubu et al., 2020). Table 4 illustrates that the HTMT indexes for all the variables were less than 0.90; this provides additional evidence for divergent validity (Henseler et ał., 2016).

Table 2. Reliability and convergent validity

\begin{tabular}{|c|c|c|c|c|}
\hline Variables & $\alpha$ & Rho_A & CR & AVE \\
\hline Mobile Ad Wearout & .912 & .917 & .945 & .851 \\
\hline Consumer irritation & .870 & .870 & .939 & .885 \\
\hline Perceived consumer intrusiveness & .881 & .885 & .944 & .893 \\
\hline Consumer engagement & .755 & .760 & .835 & .504 \\
\hline Consumer loyalty & .728 & .818 & .834 & .627 \\
\hline
\end{tabular}

Note: $\mathrm{CR}$, composite reliability $\geq .70$. AVE, average variance extracted $\geq .50$. a, Cronbach's alpha $\geq .70$. Rho_A $\geq .70$. 
Table 3. Divergent validity using Fornell-Larcker matrix

\begin{tabular}{|llllll|}
\hline Variables & $\mathbf{1}$ & $\mathbf{2}$ & $\mathbf{3}$ & $\mathbf{4}$ & $\mathbf{5}$ \\
\hline Mobile Ad Wearout & $\mathbf{. 9 2 2}$ & & & & \\
\hline Consumer irritation & .379 & $\mathbf{. 9 4 1}$ & & & \\
\hline Perceived consumer intrusiveness & .542 & .603 & $\mathbf{. 9 4 5}$ & & \\
\hline Consumer engagement & -.110 & -.280 & -.293 & $\mathbf{. 7 1 0}$ & \\
\hline Consumer loyalty & .387 & .276 & .414 & -.110 & $\mathbf{. 7 9 2}$ \\
\hline
\end{tabular}

Note: Values above the diagonal in bold are squared inter-construct correlations for the Fornell-Larcker criterion

Table 4. Divergent validity using HTMT index

\begin{tabular}{|llllll|}
\hline Variables & $\mathbf{1}$ & $\mathbf{2}$ & $\mathbf{3}$ & $\mathbf{4}$ & $\mathbf{5}$ \\
\hline Mobile Ad Wearout & - & & & & \\
\hline Consumer irritation & .424 & - & & & \\
\hline Perceived consumer intrusiveness & .603 & .691 & - & - & \\
\hline Consumer engagement & .146 & .331 & .356 & .214 & - \\
\hline Consumer loyalty & .390 & .284 & .472 & \\
\hline
\end{tabular}

\section{Hypotheses Testing}

Concerning the effects of Mobile Ad Wearout, the findings from the PLS-SEM in Table 5 reflect a positive and significant impact of this variable on consumer irritation $(\beta=.379, \rho=.000)$, perceived consumer intrusiveness $(\beta=.542, \rho=.000)$, which corroborates hypotheses 1 and 2 , respectively. Figure 1 shows that Mobile Ad Wearout explains 14\% and 29\% of the variance of consumer irritation and perceived consumer intrusiveness. In relation to the effects of consumer irritation, a negative and significant impact of this variable on consumer engagement was obtained $(\beta=-.163, \rho=.033$ ), and the impact on consumer loyalty $(\beta=042, \rho=.638)$ was insignificant. This confirms hypothesis 3 and disconfirms hypothesi

In relation to the effects of perceiyed consumer intrusiveness, a negative and significant impact of perceived consumer intrusiveness on consumer engagement was obtained $(\beta=-.195, \rho=.004)$, as well as a positive and signifieant impact on consumer loyalty $(\beta=.389, \rho=.000)$ (see Table 5). This confirms hypothesis 5 and disconfirms hypothesis 6 . Figure 1 shows that consumer irritation and perceived consumer intrusiveness, collectively, explain $10 \%$ of the variance of consumer engagement. Whereas, perceived consumer intrusiveness explains $17 \%$ of the variance of consumer loyalty.

\section{Supplementary Analysis}

This study did not dictate nor hypothesize the presence of mediatory effects. To discover the process through which consumers seek refuge from Mobile Ad Wearout, a test for mediation was carried out. Sobel's test has been criticized for being overly conservative due to its flawed sampling distribution

\section{Table 5. Direct effects}

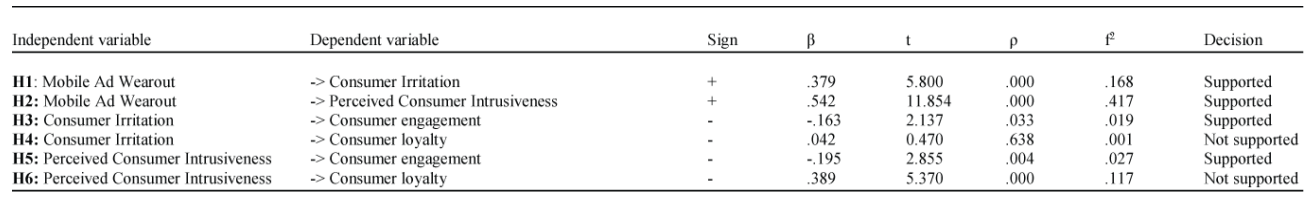

Notes: $\beta=$ coefficient; $t=t$-value; $\rho=\rho$-value $; f^{2}=$ effect size 
Figure 1. Factor loadings of the indicators, beta, and $R^{2}$ values

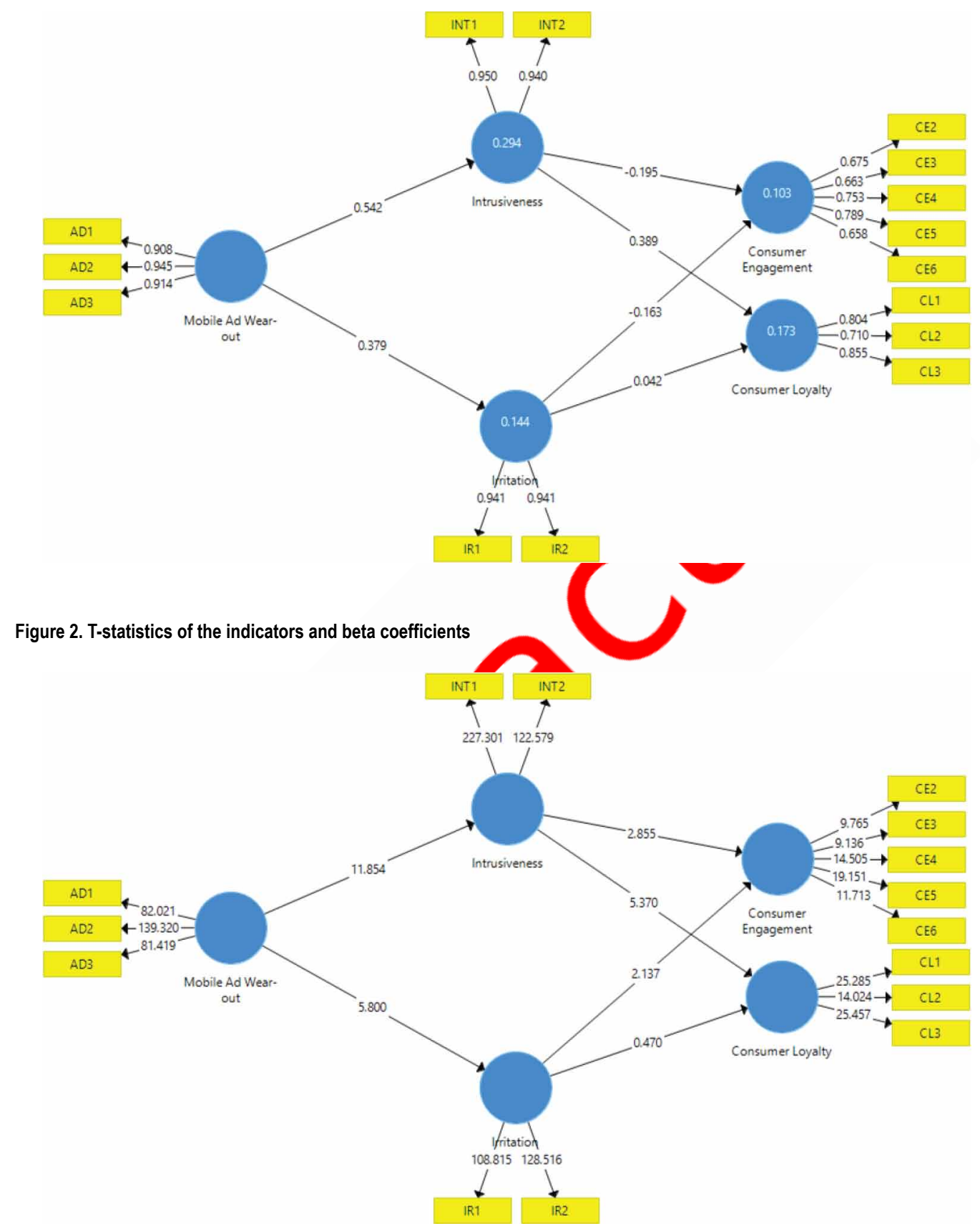

assumptions and biased estimation. Bootstrapping overcomes this problem by resampling the dataset through simulation, in other words, estimating the indirect effect in each resampled dataset using confidence intervals for the indirect effect. Thus, a more rigorous and powerful mediation test, "bootstrapping," with a resample of $n=5000$, was deployed (Zhao, Lynch, \& Chen, 2010).

To test for the indirect effects, the author(s) assessed the bias-corrected bootstrap confidence intervals. The indirect effect of Mobile Ad Wearout on consumer engagement through consumer 
irritation was $\beta=-.062, \rho=.037$ and was statistically significant at the $95 \%$ confidence interval (-.120; -.002). The indirect effect of Mobile Ad Wearout on consumer loyalty through consumer irritation was $\beta=.016, \rho=.650$ and was statistically insignificant at the $95 \%$ confidence interval $(-.053 ; .086)$. Based on these results, we conclude that consumer irritation fully mediates the link between Mobile Ad Wearout on consumer engagement and not with loyalty (see Table 6).

The indirect effect of Mobile Ad Wearout on consumer engagement through perceived consumer intrusiveness was $\beta=-.106, \rho=.007$ and was statistically significant at the $95 \%$ confidence interval (-.181; -.026). The indirect effect of Mobile Ad Wearout on consumer loyalty through perceived consumer intrusiveness was $\beta=.211, \rho=.000$ and was statistically significant at the $95 \%$ confidence interval $(.127 ; .304)$. Based on these results, we conclude that perceived consumer intrusiveness fully mediates the link between Mobile Ad Wearout and consumer engagement, and link between Mobile Ad Wearout and consumer loyalty (see Table 6).

\section{DISCUSSION}

In this study, we examine how Mobile Ad Wearout experienced by consumers influenees their irritation and perceived intrusiveness. We went further to examine how increased itritation and perceived intrusiveness may lower consumer engagement and loyalty. First, Mobile Ad Wearout influences consumer irritation and perceived consumer intrusiveness. It is worth noting that our findings are consistent with prior work (Brechman et al., 2016; Kronrod \& Huber, 2019; Tsai et al., 2011; Tucker, 2014). The present findings validate those tested for offline Ad Wearout and in Western nations. This gives scope to a broader theoretical view of the consequences of Mobile Ad Wearout on consumer responses in the Arabian culture.

Second, we found that irritation reduces constumer engagement. This implies that events such as disappointment and irritation contribute negatively to engagement and involvement with a firm or brand. This makes sense, as consumers' attachment to a brand drives engagement (Hinson et al., 2019), so a decline in attachment may result in lower levels of engagement. This outcome is consistent with prior work, which shows that negative emotions such as anger, discontent, dislike, and worry can result in unwanted behavioral responses such as switching, complaining, and negative WOM among consumers (e.g., Romani et al., 2012; Sung \& Yih, 2019). We extend the literature to mobile ads domain by showing how irritation result in unwanted behavioral responses such as lower consumer engagement. Although existing literature has theorized a negative association between irritation and loyalty (e.g, Grewal et a1, 2016; Schmidt \& Eisend, 2015), it appears that irritation did not reduce consumerloyalty. Similar findings were echoed by Magin et al. (2003). Nordhielm (1996, p. 2) added that "people's affective response to an overexposure of ads or marketing campaigns is either no longer positive or it shows a significant decline." A plausible reason can be that irritation is at stake, or people are in an unchangeable mode. Nonetheless, further empirical research is needed, considering contextual variables such as switching barriers, frequency of ads, cyber culture, time spent with a mobile, service, and product quality.

Third, we found that perceived consumer intrusiveness reduces consumer engagement. This implies that consumers' heightened privacy and intrusion concerns weaken their engagement with a

Table 6. Indirect effects

\begin{tabular}{|c|c|c|c|}
\hline Indirect effects & Coefficients & t-value & $\rho$-value \\
\hline Mobile Ad Wearout $->$ Consumer Irritation $->$ Consumer engagement & -.062 & 2.086 & .037 \\
\hline Mobile Ad Wearout $\rightarrow$ Consumer Irritation $\rightarrow$ Consumer loyalty & .016 & 0.453 & .650 \\
\hline Mobile Ad Wearout -> Perceived Consumer Intrusiveness-> Consumer engagement & -.106 & 2.699 & .007 \\
\hline Mobile Ad Wearout -> Perceived Consumer Intrusiveness-> Consumer loyalty & .211 & 4.656 & .000 \\
\hline
\end{tabular}


firm or brand. Prior scholars recorded a negative and significant association between similar variables such as click-rates and website-revisit intention (e.g., Aguirre et al., 2015; Grewal et al., 2016; Schmidt \& Eisend, 2015) as well as perceived mobile app intrusion and usage behavior (Amos et al., 2014). This study has provided additional evidence, using consumer engagement as an outcome. In addition, we recorded a positive and significant relationship between perceived consumer intrusiveness and consumer loyalty. The present outcome delineates that as perceived consumer intrusiveness increases, consumer loyalty towards the firm or brand increases. This contradicts the initial prediction, as we expected consumer loyalty to decline. The conflicting result illustrates a need to further investigate the role of contextual variables such as information sensitivity of the consumers, number of alternative brands, switching barriers, frequency of ads, cyber culture, time spent with a mobile, and quality.

\section{Implications for Theory and Practice}

Several implications were drawn from the findings. First, the findings suggest that mobile marketing campaigns in Jordan should be done with tactics to make the ads and marketing informationenjoyable and fresh in consumer minds; this way, irritation and intrusion perception can be avoided. Prior research shows that Mobile Ad Wearout is less likely to occur with lesser-known brands, as additional exposures may still be informative (Försch \& de Haan, 2018; Srinivasan \& Hanssens, 2009). In this view, firms may categorize consumers based on the level of their engagement; that is, highly engaged consumers should have minimal exposure to mobile ads, while those with a low level of engagement can be exposed to additional ads to stimulate a taste for the eompany's product or services.

Second, marketers may adopt a strategy by which consumers are repeatedly exposed to mobile ads with limited interruption, with ample variations in execution to evadeirritation and annoyance (Försch \& de Haan, 2018). Further, advertising-variation strategies have been shown to be more effective in terms of recall and thus can be useful tools for marketers in that they can lead to synergistic effects (Gebreselassie \& Bougie, 2019). Third, managers must balance marketing campaigns to leverage the benefits of mobile ads and evade their consequential effects. For instance, mobile ads that provide justification for their offers stand a chance of boosting consumer loyalty and engagement (Grewal et al., 2016). To achieve this, ads should not appear in a self-serving or manipulative manner, because ads' presentations can influence marketing campaign efforts and privacy concerns. The use of a recommender system and online referrals (Abubakar et al., 2016) can help mitigate consumer backlash triggered by perceptions of invasive and/or targeted ads.

Another interesting business inplication is the inclusion of fun, interactive, and entertaining content in mobile marketing and ads, as it is likely to reduce negative and induce positive reactions. Arabs in general share a similar culture and have greater tendency for homogeneity and group conformity (Hofstede, Hofstede, \& Minkov, 2005). A study by Mahajan (2013) found that Arabian consumers share similar traits and often react to a specific marketing mix in similar ways and manners. Although a "one size fits all" strategy may not work for all Arabian consumers and countries, the findings in the Jordanian context provides important marketing-mix insights for managers in countries with similar demographic and cultural features. For example, marketing managers in countries such as Lebanon, Egypt, and Saudi Arabia can benefit from the unveiled insights in this study. In sum, our findings show that for marketing ads and campaigns that are sent within short time intervals, such campaigns should have a planned time lag after the initial exposure to minimize negative reactions. The use of the simple random sampling technique and a suitable sample selection, using filter questions, allowed the researchers to obtain responses from a representative sample. In addition, a set of stringent statistical tests to establish reliability and validity of the measures were conducted. In sum, the extant methodological and statistical approaches ensured the robustness of the method, and they also allowed the researchers to make concrete inferences based on the outcomes. 


\section{Limitations and Future Research Directions}

This study has several limitations that are worth mentioning. First, we cannot ascertain causal order, because the data are cross-sectional. Second, the study uses a self-reported approach, which is vulnerable to common method bias. Third, single-source data, as respondents are all from a single country and culture, limits our ability to generalize the findings. Fourth, the present study did not consider important contextual variables. To wrap up, we recommend that future studies utilize advanced methods such as longitudinal and experimental design (Podsakoff et al., 2012; Zhao et al., 2010), fuzzy sets (Kaya et al., 2020), Bayesian networks (Wipulanusat et al., 2020), and predictive analytics and artificial intelligence techniques (Abubakar, 2018, 2019). How the findings generalize to other cultural contexts warrants further research; thus, researchers are encouraged to consider the following contextual variables: information sensitivity of the consumers, number of alternative brands, switching barriers, frequency of ads, cyber culture, time spent with a mobile, service, and product quality.

\section{CONCLUSION}

This study investigated the impact of Mobile Ad Wearout on Jordanian consumer irritation and perceived intrusiveness, and their impacts on consumer engagement and loyalty. Stringent tests and robust methodological approaches were carried out; results revealed that Mobile Ad Wearout is a strong determinant for increased irritation and perceived intrusiveness among consumers. Results show that as consumer irritation increases, the level of consumer engagement decreases, and no change was recorded for consumer loyalty. Further, as perceiyed intrusiveness increases, the level of consumer engagement decreases, and the level of consumer loyalty increases. Marketing managers should consider both the positive and negative fronts of mobile ads prior to inaugurating them into their marketing mix.

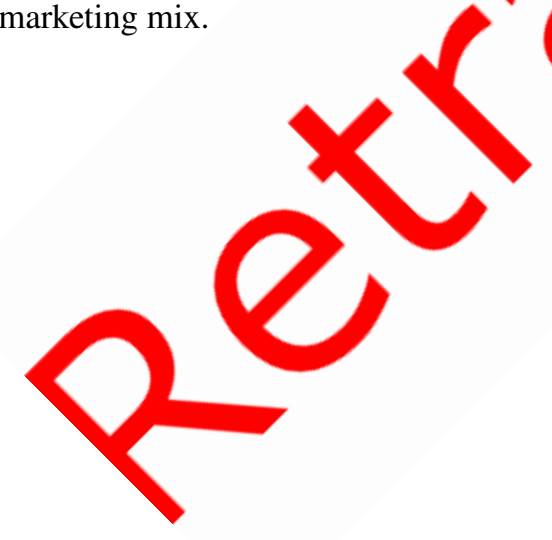




\section{REFERENCES}

Aaker, D. S., \& Donald, E. B. (1985). Causes of Irritation in Advertising. Journal of Marketing, 49(2), 47-57. doi:10.1177/002224298504900204

Abubakar, A. M. (2018). Linking work-family interference, workplace incivility, gender and psychological distress. Journal of Management Development, 37(3), 226-242. doi:10.1108/JMD-06-2017-0207

Abubakar, A. M. (2019). Using hybrid SEM-artificial intelligence approach to examine the nexus between boreout, generation, career, life and job satisfaction. Personnel Review, 49(1), 67-86. doi:10.1108/PR-06-2017-0180

Abubakar, A. M., \& Al-zyoud, M. F. (2020). Problematic Internet usage and safety behavior: Does time autonomy matter? Telematics and Informatics.

Abubakar, A. M., Ilkan, M., Al-Tal, R. M., \& Eluwole, K. K. (2017). eWOM, revisit intention, destination trust and gender. Journal of Hospitality and Tourism Management, 31, 220-227. doi:10.1016/j.jhtm.2016.12.005

Abubakar, A. M., Ilkan, M., \& Sahin, P. (2016). eWOM, eReferral and gender in the virtual community.Marketing Intelligence \& Planning, 34(5), 692-710. doi:10.1108/MIP-05-2015-0090

Aguirre, E., Mahr, D., Grewal, D., de Ruyter, K., \& Wetzels, M. (2015). Unraveling the personalization paradox: The effect of information collection and trust-building strategies on online advertisement effectiveness. Journal of Retailing, 91(1), 34-49. doi:10.1016/j.jretai.2014.09.005

Alwitt, L. F., \& Mitchell, A. A. (1985). Psychological Processes and Advertising Effect: Theory, Research, and Applications. Lawrence Erlbaum Associates.

Amos, C., Zhang, L., \& Pentina, I. (2014). Investigating privacy perception and behavior on Weibo. Journal of Organizational and End User Computing, 26(4), 43-56. doi:10.4018/joele.2014100103

Antonetti, P. (2016). Consumer anger: A label in search of meaning. European Journal of Marketing, 50(9/10), 1602-1628. doi:10.1108/EJM-08-2015-0590 Arya, K. V., \& Bhadoria, R. S. (Eds.). (2019). The Biometric Computing: Recognition and Registration. CRC
Press.

Arya, K. V., Bhadoria, R. S., \& Chaudhari, N. S. (Eds). (2018). Emerging Wireless Communication and Network Technologies: Principle, Paradigm and Performance. Springer. doi:10.1007/978-981-13-0396-8

Bacile, T. J., Ye, C., \& Swilley, E. (2014).From Firm-controlled to Consumer contributed: Consumer Coproduction of Personal Media Marketing Communication. Journal of Interactive Marketing, 28(2), 117-133. doi:10.1016/j.intmar.2013.1

Bauer, R. A., \& Stephen, A. G. (1968). Advertising in American: The Consumer View. Harvard University.

Benes, R. (2019).Driven by Social, Native Accounts for Nearly Two-Thirds of Display Ad Spend. Retrieved from https://www.emarketer.com/content/driven-by-social-native-accounts-for-nearly-two-thirds-of-display-ad-spend

Bhadoria, R. S., Chaudhari, N., Tomar, G. S., \& Singh, S. (Eds.). (2017). Exploring Enterprise Service Bus in the Service-Oriented Architecture Paradigm. IGI Global. doi:10.4018/978-1-5225-2157-0

Brechman, J., Bellman, S., Robinson, J. A., Rask, A., \& Varan, D. (2016). Limited-Interruption Advertising in Digital-Video Content: An Analysis Compares the Effects of "Midroll" Versus "Preroll" Spots and Clutter Advertising. Journal of Advertising Research, 56(3), 289-298. doi:10.2501/JAR-2016-001

Broussard, G. (2000). How advertising frequency can work to build online advertising effectiveness. International Journal of Market Research, 42(4), 1-13. doi:10.1177/147078530004200406

Cacioppo, J. T., \& Petty, R. E. (1979). Effects of message repetition and position on cognitive response, recall, and persuasion. Journal of Personality and Social Psychology, 37(1), 97-109. doi:10.1037/0022-3514.37.1.97

Chen, J., Yang, X., \& Smith, R. E. (2016). The effects of creativity on advertising wear-in and wear-out. Journal of the Academy of Marketing Science, 44(3), 334-349. doi:10.1007/s11747-014-0414-5

DatarePortal. (2020). Digital 2020: Jordan. https://datareportal.com/reports/digital-2020-jordan 
Di Gangi, P. M., \& Wasko, M. M. (2016). Social media engagement theory: Exploring the influence of user engagement on social media usage. Journal of Organizational and End User Computing, 28(2), 53-73. doi:10.4018/JOEUC.2016040104

Dickinger, A., Haghirian, P., Murphy, J., \& Scharl, A. (2004, January). An investigation and conceptual model of SMS marketing. In System Sciences, 2004. Proceedings of the 37th annual Hawaii international conference. IEEE.

Duncan, C. P., \& Nelson, J. E. (1985). Effects of humor in a radio advertising experiment. Journal of Advertising, 14(2), 33-64. doi:10.1080/00913367.1985.10672944

eMarketer. (2015). Number of Companies Using Instagram To Nearly Double Next Year Will surpass Twitter in 2017. Retrieved from https://www.emarketer.com/Article/Number-of-Companies-Using-Instagram-NearlyDouble-Next-Year/1013122

Fornell, C., \& Larcker, D. F. (1981). Evaluating structural equation models with undobservable variables and measurement error. Journal of Marketing Research, 18(1), 39-50.

Försch, S., \& de Haan, E. (2018). Targeting online display ads: Choosing their frequency and spacing. International Journal of Research in Marketing, 35(4), 661-672.

Gebreselassie, A. W., \& Bougie, R. (2019). Increasing the effectiveness of advertisements targeting social issues in least developed countries. Journal of Social Marketing, 9(2), 225-25

Goldstein, D. G., Suri, S., McAfee, R. P., Ekstrand-Abueg, M., \&Diaz, F. (2014). The economic and cognitive costs of annoying display advertisements. JMR, Journal of Marketing Research, 51(6), 742-752.

Grewal, D., Bart, Y., Spann, M., \& Zubcsek, P. P. (2016). Mobile advertising: A framework and research agenda. Journal of Interactive Marketing, 34, 3-14.

Gupta, B. B., Agrawal, D. P., \& Yamaguchi, S. (2019). Deeplearning models for human centered computing in fog and mobile edge networks. Journal of Ambient. Intelligence and Humanized Computing, 10, 2907-2911. https://doi.org/10.1007/s12652-018-0919-8

Gupta, B. B., Yamaguchi, S., \& Agrawal, D.P. (2018). Adyances in security and privacy of multimedia big data in mobile and cloud computing. Multimedia Tools and Applications, 77(7), 9203-9208.

Ha, L. (1996). Advertising Clutter in Consumer Magazines: Dimensions and Effects. Journal of Advertising Research, 36(July/August), 76

Hair, J. F., Hult, G. T. M., Ringle, C.M., \& Sarstedt, M. (2017). A primer on partial least squares structural equation modeling (PLS-SEM) (2nd ed.). Sage.

Henseler, J., Hubona, G. \& Ray, P. A. (2016). Using PLS path modeling in new technology research: Updated guidelines. Industrial Management \& Data Systems, 16(1), 2-20.

Hinson, R., Boateng, H., Rênner, A., \& Kosiba, J. P. B. (2019). Antecedents and consequences of customer engagement on Kacebook: An attachment theory perspective. Journal of Research in Interactive Marketing.

Hofstede, G. H., Hofstede, G. J., \& Minkov, M. (2005). Cultures and organizations: Software of the mind (Vol. 2). Mcgraw-hill.

Hollebeek, L. D., Glynn, M. S., \& Brodie, R. J. (2014). Consumer brand engagement in social media: Conceptualization, scale development and validation. Journal of Interactive Marketing, 28(1), 149-165.

Internetworldstats. (2020). Internet Growth and Population Statistics. Retrieved from https://www. internetworldstats.com/list2.htm

Jahmani, K., Fadiya, S. O., Abubakar, A. M., \& Elrehail, H. (2018). Knowledge content quality, perceived usefulness, KMS use for sharing and retrieval. VINE Journal of Information and Knowledge Management Systems, 48(4), 470-490. https://doi.org/10.1108/VJIKMS-08-2017-0054

Jararweh, Y., Alsmirat, M., Al-Ayyoub, M., Benkhelifa, E., Darabseh, A., Gupta, B., \& Doulat, A. (2017). Software-defined system support for enabling ubiquitous mobile edge computing. The Computer Journal, 60(10), 1443-1457. 
Kaya, B., Abubakar, A. M., Behravesh, E., Yildiz, H., \& Mert, I. S. (2020). Antecedents of innovative performance: Findings from PLS-SEM and fuzzy sets (fsQCA). Journal of Business Research, 114, 278-289.

Kaya, B., Behravesh, E., Abubakar, A. M., Kaya, O. S., \& Orús, C. (2019). The moderating role of website familiarity in the relationships between e-service quality, e-satisfaction and e-loyalty. Journal of Internet Commerce, 18(4), 369-394.

Keiningham, T., Aksoy, L., \& Williams, L. (2009). Why loyalty matters. BenBella Books.

Kirmani, A. (1997). Advertising repetition as a signal of quality: If it's advertised so much, something must be wrong. Journal of Advertising, 26(3), 77-86.

Kleinig, J. (2009). Loyalty. In E. N. Zalta, U. Nodelman, \& C. Allen (Eds.), Stanford Encyclopedia of Philosophy (Spring 2009 Edition). Metaphysics Research Lab, CSLI. Stanford University. https://plato.stanford.edu/archives/ spr2009/entries/loyalty

Kronrod, A., \& Huber, J. (2019). Ad Wearout Wearout: How time can reverse the negative effect of frequent advertising repetition on brand preference. International Journal of Research in Marketing, 36(2), 306-324.

Li, H., Edwards, S. M., \& Lee, J. H. (2002). Measuring the intrusiveness of advertisements: Scale development and validation. Journal of Advertising, 31(2), 37-48.

Lin, H., \& Chen, Z. (2015). Influence of SMS advertising on consumer behayioral intention. Journal of Organizational and End User Computing, 27(4), 25-42.

Magin, S., Algesheimer, R., Huber, F., \& Herrmann, A. (2003). The impact of brand personality and customer satisfaction on customer's loyalty: Theoretical approach and findings of a causal analytical study in the sector of internet service providers. Electronic Markets, 13(4), 294-308.

Mahajan, V. (2013). Understanding the Arab consumer. Harvard Business Review, 91(5), 128-133.

Naik, P.A., Mantrala, M.K., \& Sawyer, A.G. (1998). Planning media schedules in the presence of dynamic advertising quality. Marketing Science, 17(3), 2

Noble, S. M., Griffith, D. A., \& Adjei, M T. (2006). Drivers of local merchant loyalty: Understanding the influence of gender and shopping motives. Journal of Retailing, 82(3), 177-188.

Nordhielm, C. L. (1996). A dual process model of advertising repetition effects. Visual Persuasion. Norwood, NJ: Lawrence Erlbaum Associates.

Pechmann, C., \& Stewart, D. W. (1990). The effects of comparative advertising on attention, memory, and purchase intentions. The Journal of Consumer Research, 17(2), 180-191.

Peggy, M. (1999). The Wearout Phenomenon. Marketing Research, 11(3), 26-32.

Podsakoff, P. M., MacKenzie,S.B., \& Podsakoff, N. P. (2012). Sources of method bias in social science research and recommendations on how to control it. Annual Review of Psychology, 63, 539-569.

Rau, P. L. P., Zhou, J., Chen, D., \& Lu, T. P. (2014). The influence of repetition and time pressure on effectiveness of mobile advertising messages. Telematics and Informatics, 31(3), 463-476.

Riaz, Z., \& Khan, M. I. (2016). Impact of service failure severity and agreeableness on consumer switchover intention: Mediating role of consumer forgiveness. Asia Pacific Journal of Marketing and Logistics, 28(3), 420-434.

Ringle, C.M., Wende, S., \& Becker, J.M. (2015). SmartPLS 3. Boenningstedt: SmartPLS GmbH.

Romani, S., Grappi, S., \& Dalli, D. (2012). Emotions that drive consumers away from brands: Measuring negative emotions toward brands and their behavioral effects. International Journal of Research in Marketing, 29(1), 55-67.

Royo-Vela, M., \& Luna, G. (2012). The antecedents of negative consumers' attitudes toward SMS advertising: A theoretical framework. Palma de Mallorca: Actas delXXIV Encuentro de Profesores de Marketing.

Royo-Vela, M., \& Meyer, F. (2016). Exploring Wearout and Some Insights and Replies to Factors Affecting Irritation and Attitudes towards Mobile Advertising. In Advertising in New Formats and Media: Current Research and Implications for Marketers (pp. 211-241). Emerald Group Publishing Limited. 
Schmidt, S., \& Eisend, M. (2015). Advertising repetition: A meta-analysis on effective frequency in advertising. Journal of Advertising, 44(4), 415-428.

Segal, J., \& Morris, C. (2011). Scientific end-user developers and barriers to user/customer engagement. Journal of Organizational and End User Computing, 23(4), 51-63.

Shanahan, T., Tran, T. P., \& Taylor, E. C. (2019). Getting to know you: Social media personalization as a means of enhancing brand loyalty and perceived quality. Journal of Retailing and Consumer Services, 47, 57-65.

Shankar, A., \& Jebarajakirthy, C. (2019). The influence of e-banking service quality on customer loyalty: A moderated-mediation approach. International Journal of Bank Marketing.

Shawky, S., Kubacki, K., Dietrich, T., \& Weaven, S. (2019). Using social media to create engagement: A social marketing review. Journal of Social Marketing, 9(2), 204-224.

Shmueli, G., Sarstedt, M., Hair, J. F., Cheah, J. H., Ting, H., Vaithilingam, S., \& Ringle, C. M. (2019). Predictive model assessment in PLS-SEM: Guidelines for using PLS predict. European Journal of Marketing, 53(11), 2322-2347. https://doi.org/10.1108/EJM-02-2019-0189

Srinivasan, S., Pauwels, K., Silva-Risso, J., \& Hanssens, D. M. (2009). Product innovations, advertising, and stock returns. Journal of Marketing, 73(1), 24-43.

Statista. (2019). Number of social network users worldwide from 2010 to 2021 (in billions). Retrieved from https://www.statista.com/statistics/278414/number-of-worldwide-social-network-users/

Sung, B., \& Yih, J. (2019). The direct and indirect effects of anger and its cognitive appraisals in public relations incidents. Asia Pacific Journal of Marketing and Logistics, 3Y(5),1344-1358. https://doi.org/10.1108/ APJML-08-2018-0292

Triantafillidou, A., \& Siomkos, G. (2018). The impact of Facebook experience on consumers' behavioral Brand engagement. Journal of Research in Interactive Marketing, 12(2), 164-192.

Tsai, J. Y., Egelman, S., Cranor, L., \& Acquisti, A. (2011). The effect of online privacy information on purchasing behavior: An experimental study. Information Systems Research, 22(2), 254-268.

Tucker, C. E. (2014). Social networks, personalized advertising, and privacy controls. JMR, Journal of Marketing Research, 51(5), 546-562.

Walrave, M., Poels, K., Antheunis, M. L, Van den Broeck, E., \& van Noort, G. (2018). Like or dislike? Adolescents' responses to personalized social network site advertising. Journal of Marketing Communications, 24(6), 599-616.

Wipulanusat, W., Panuwatwanich, K., Stewart, R. A., Arnold, S. L., \& Wang, J. (2020). Bayesian network revealing pathways to workplace innovation and career satisfaction in the public service. Journal of Management Analytics, Z(2), 253-280.

Yakubu, M. N. Dasuki, S. I., Abubakar, A. M., \& Kah, M. M. (2020). Determinants of learning management systems adoption in Nigeria: A hybrid SEM and artificial neural network approach. Education and Information Technologies, 1-25.

Zhao, X., Lynch, J. G. Jr, \& Chen, Q. (2010). Reconsidering Baron and Kenny: Myths and truths about mediation analysis. The Journal of Consumer Research, 37(2), 197-206. 


\section{APPENDIX}

Table 7. Research Instruments

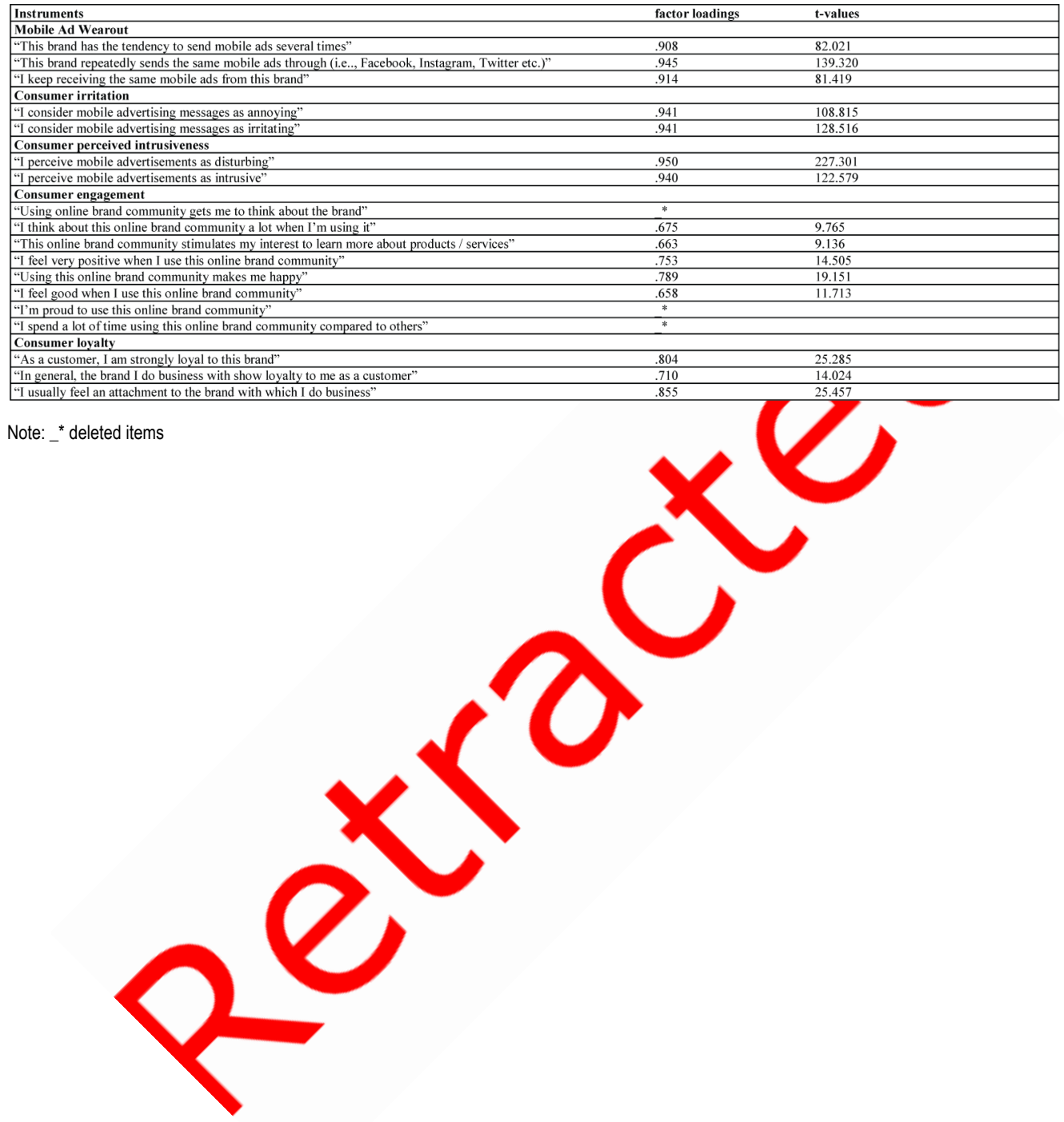

Ahmad A.M. Alwreikat is affiliated with Cyprus International University.

Husam Rjoub $(P h D)$ is attached to the Faculty of Economics and Administrative Sciences, Cyprus International University. 